\title{
Chapter 13 \\ Learning for All: Lessons from ASER \\ and Pratham in India on the Role \\ of Citizens and Communities \\ in Improving Children's Learning
}

\author{
Rukmini Banerji
}

\section{Abbreviations}

ASER Annual Status of Education Report

NEP New Education Policy

SMS short message service

TaRL Teaching-at-the-Right-Level

\subsection{Introduction}

Around the turn of the century, global attention as well as national policy in most developing countries were focused on expanding school enrollment and universalizing primary education. Children who were "left out" of school were "visible", and strategies on how to bring them into school were developed based on local contexts and needs. But as more and more children were enrolled in school, a more "invisible" problem was sensed: children getting "left behind". Despite being in school, many were not at the level expected of them at their grade. Teachers tried to grapple with this fact in classroom transactions. Parents, often not very educated themselves, were frustrated with their children's lack of progress.

The success of universalizing primary schooling can be attributed to both government efforts to provide schooling, and to parents who enrolled their children. These efforts were based on a common understanding of what schooling entailed. "Every child in school" was a goal that governments and citizens could relate to and work toward. Similarly, to enable "every child to learn well", a shared vision was

\footnotetext{
R. Banerji ( $\otimes)$

Pratham Education Foundation, Mumbai, India

e-mail: rukmini.banerji@pratham.org

$\mathrm{S}$. Ra et al. (eds.), Powering a Learning Society During an Age of Disruption,

Education in the Asia-Pacific Region: Issues, Concerns and Prospects 58,

https://doi.org/10.1007/978-981-16-0983-1_13
} 
needed. The problem of being left behind needs to be visible, to be clearly identified, and to be articulated in a way that most people could understand.

This chapter highlights a set of experiences from the last 20 years in India of how community-based learning assessments helped in raising awareness at the local level, at the same time influencing policy and practice at the macro level. The chapter analyzes how community involvement can fill the gap in the education system using past experiences, as well as recent lessons from the coronavirus disease (COVID-19) crisis. The discussion points to promising directions for how societies can learn to deal with disruptions and discontinuities, and identifies ways in which a broader set of actors can play a role in helping children learn.

\subsection{Origins of Community-Based Learning Assessment}

Pratham Education Foundation, a civil society organization, started its work in India around 1994, with the mission of "every child in school and learning well". ${ }^{1}$ Even before the new millennium, a large part of Pratham's efforts concentrated on how to help children who were already in school but not learning. As these activities gathered steam, it became clear that inability to read was a critical stumbling block. If a child could not read, he or she could not progress in the school system. If a child had not picked up basic reading proficiency by grade 2 or 3 , then the chances of falling behind were high. In India, there were no examinations in primary school that assessed learning levels in the early grades. Children moved automatically from one grade to the next. The dynamics of the downward spiral were straightforward-as the pace of the curriculum got faster, as content become more difficult, and grade level expectations got higher, the child slipped further and further back academically.

To arrest this learning slide, and to help the child "catch up", Pratham developed a "learning to read" technique that helped children aged 7 or 8 and above learn to read in about 6-8 weeks (with focused time of about 2 hours a day). A key element of this approach was to start with a clear understanding of where the child was. The instructor spent time with each child one-on-one, individually working on a few simple reading tasks. The child was asked to recognize letters, then to try reading a set of simple common words in everyday use. The tasks were progressive, moving from easy to more difficult. The next task was to read a four-sentence paragraph at the grade 1 level of difficulty. The final and "highest" level was a short story of 8-10 sentences, very much like texts found in grade 2 textbooks. This assessment was essential before the instructor or teacher could start instructional activities. In a matter of a few minutes, the teacher had a good sense of each child but also of the composition of the group of children in terms of the distribution of their current reading abilities. (A similar assessment was done for arithmetic.)

\footnotetext{
${ }^{1}$ Pratham works in the field of children's education and youth skilling in India. For more information see www.pratham.org.
} 
The assessment was followed by a set of activities that helped the child move from his or her current level to the next level of reading. The instructor could periodically track progress of each child, and also of the entire group. This approach is now well known as Teaching-at-the-Right-Level or TaRL (see discussion in Sect. 5).

The reading assessment also led to other interactions that had not been originally anticipated. For example, parents often asked what was being done. To explain the objective of the exercise to uneducated or often illiterate parents, it was easy to point to the "story" level text and read it aloud. This demonstrated to them what the goal of exercise was. For many parents, this was the "a-ha" moment. They would shake their heads and say, "So now I know what my child is supposed to learn in school".

The learning to read tool helped to demystify "learning". It enabled parents, families, and communities to understand the problem and clearly see the goal of what was being attempted. The assessment helped to make a felt problem "visible" and in so doing, opened up the possibilities of devising solutions (Banerji 2013; Banerji et al. 2013).

\subsection{Scaling up Community-Based Learning Assessments: The Journey of the Annual Status of Education Report}

A "schooled" society would not by itself lead to a "learning" society. The focus on "every child in school" needs to shift to "learning for all". Among planners, policy makers, practitioners, and parents, the basic assumption is that schooling would automatically lead to learning. This notion has to be challenged; people have to see that under current circumstances, something different has to be done.

If a simple set of tasks can enable a teacher to quickly understand the foundational learning level of a child and help the child's parents figure out where their child stands, then by the same logic, such a testing tool and process can be used in a community to establish the learning status of all children, or a district to get a sense of how children in the district are faring. This is the idea behind preparing society to get ready for "every child learning well". The basic testing tool and the simple process of assessment, described in the previous section, formed the core for launching what is now well known as the Annual Status of Education Report (ASER).

To put "learning for all" on the education agenda, it was important to make ordinary people, especially parents, learn about the status of children's learning either by using simple tools themselves or by digesting results available for their localities. The ASER tool and assessment process is a good example of how ordinary people can participate in and contribute toward evidence-based problem solving.

Could a citizen-led, community-based assessment exercise influence how a country perceives children's schooling and learning? When Pratham launched the first ASER initiative in 2005, this was the objective. The architecture of ASER was designed to engage individuals and institutions in each district in India in preparing a status report on schooling and learning. The underlying idea was that if local 
people participate in understanding the problem, they will also discuss possible solutions, and many will push the government and themselves to find answers to the questions before them. To ensure widespread participation of citizens, the metrics and methods of assessment were kept easy to understand and not complicated to execute. Modes and mechanisms of training, monitoring, reporting, and disseminating were straightforward. Right from the start until the present, the balance between simplicity and rigor was strictly maintained and the cost of the entire exercise kept as frugal as possible.

From inception, the goal of ASER was to cover all $600+$ rural districts in India with a sufficient sample to be able to generate reliable district-level estimates of schooling and basic learning (reading and arithmetic), as well as state and national figures. (Interestingly, there are hardly any district-level estimates in any social sector domain in India. Even the government's National Sample Survey data is at a "regional" level where an aggregation of several districts makes up the unit). The ASER reports were the first in India to annually bring out current figures on reading and basic arithmetic for children across the elementary school age group for each district, state, and for all of India. The participatory citizen-led exercise assumed that if people together learned what the problem was, then solutions would follow.

From 2005 to 2014 and then in 2016 and 2018, ASER has reached between 500,000 to 700,000 children annually. Across the country, more than 25,000 volunteers from approximately 500 institutions partner with ASER each year. In every district, a local organization or institution participates in the effort. Anywhere between 30 to 60 surveyors go in pairs to 30 randomly selected villages in the district to survey children in 20 randomly selected households in the sampled village. The results from each district are put together in the form of state reports and a national report.

From preparation to launch, the ASER cycle is about 100 days. Without fail, the report is released in mid-January every year. From 2005 to 2014, the main nationwide ASER was done annually. From 2014, it has been conducted every other year (see Box 13.1).

\section{Box 13.1 The ASER Village Survey Process}

The Annual Status of Education Report (ASER) starts with a pair of volunteers who will go to a village to conduct the survey. Each pair is given a village pack that contains "all the tools, formats, instructions, and communications materials to be used in the village" (Source http://www.asercentre.org/p/231.html). The survey in a village is conducted over 2 days, normally on Saturday and Sunday. On day one, the volunteers usually visit the village head to apprise him or her of the purpose of their visit. They then proceed to the village school to collect school information, talk to people, and map the village.

In mapping the village, the volunteers divide the village into four sections or hamlets, and use their " 5 th household rule" to sample 20 households: five from each of the four divisions or hamlets. They collect basic information 
from each household and assess the reading and arithmetic skills of children in that household belonging to the target age group of 5-16 years. This data collection process is monitored by the master trainers, and a high proportion of the entire set of responses are rechecked using different methods. After verification, the data comes to the central team, which analyzes it to produce the ASER Centre's Annual Status of Education Reports. These reports have had a notable and undeniable impact on India's education policy.

Source Pratham Education Foundation.

In the Indian social sector where good quality data collection is still a major challenge, ASER's practices of community mobilization and logistical management are exemplary. ASER volunteers are trained at the district level by master trainers who themselves have been trained rigorously at the state level. The actual volunteer training lasts for 2-3 days, with 1 day devoted to field practice. At the end of the training period, volunteers take a test or a quiz. Only those who have participated satisfactorily in training, showed good practical understanding in the field, and who performed well in the quiz are selected to go ahead with the actual survey.

One of the key reasons behind ASER's scalability across rural India has been the simplicity of its tools to measure learning outcomes. The reading and math assessment tools ${ }^{2}$ are designed to be simple, quick, and cost-effective "floor tests", rather than grade-level tests, and are used face-to-face, one-on-one, orally, and individually with each child. ${ }^{3}$ Many empirical studies (see Vagh 2012) have confirmed the reliability and validity of ASER tools.

Doing ASER is easy. Understanding the results is straightforward. Using the same tool is possible for a school or for a neighborhood. The availability of these tools in the public domain (on the ASER Centre website) and in 20 Indian languages makes it a national resource. ${ }^{4}$ These features have also enabled the ASER approach and architecture to be transplanted and adapted in over 15 countries for over a decade. Together this people's movement has come to be called "citizen-led assessments". 5

\footnotetext{
${ }^{2}$ See ASER Centre. ASER reading tools. http://www.asercentre.org/p/141.html.

${ }^{3}$ The highest level is a grade 2 level text, which is in the form of a short story.

${ }^{4}$ Apart from its use in the actual ASER survey, over the years, the ASER tools have been used in many other ways, e.g., in village report cards, research studies, impact evaluations, and measurement of change in ongoing programs; as well as by a variety of government and other agencies in the education space and in the social sector more widely.

${ }^{5}$ See People's Action for Learning. www.palnetwork.org for details of how ASER-like citizen led assessment initiatives have spread to other countries in South Asia, sub-Saharan Africa, and to Mexico and Nicaragua.
} 


\subsection{Translating Assessment into Action: Mobilizing for Learning}

It takes a village to raise a child.

What would it take to move policy and practice beyond schooling to learning? The ASER journey describes how a simple assessment that originated as an integral part of instructional practice — of teaching children to read-grew to be a mechanism for a country to understand a major problem.

What about moving from assessment to action? What role could ordinary people play in this process? How can people, many of whom did not have much education themselves, start to engage with "children's learning"? Going back to the history of large-scale campaigns for school enrollment, it is clear that forces have been at play both on the demand and supply side. Without government providing schools, and without parents demanding schooling, enrollment levels would not have reached the high levels we see today. Thus, for any large-scale effort to succeed, the mission needs to be owned and driven by those who want the change.

The contemporary education discourse is becoming preoccupied with issues like twenty-first century skills and emerging technologies. In India, it is only in the last 10 years or since 2010 , that in many households, for the first time, a family member has been able to complete 8 years of schooling and reach the end of the elementary stage. In this context, it is essential both for the future of the individual, of the family, and of the country, that these 8 years of schooling translate successfully into an equivalent 8 years of learning. Current estimates from India suggest that even after 5 years of schooling, less than half of all children are able to reach learning levels expected of children in grade $2 .{ }^{6}$ While most parents understand the importance of "schooling", and know how to support their children's schooling, they often do not understand how they could contribute to "learning" or how to create a supportive learning environment at home.

\subsection{Current Interventions: Village Ownership for Children's Learning}

By definition, a "learning society" is one that promotes a culture of lifelong learning and enables ordinary people to learn and to support others to learn as well. For uneducated or poorly educated parents, what would help them to engage first with their own children's learning journey and then later to work toward imagining what a learning community could be like?

\footnotetext{
${ }^{6}$ See ASER reports including ASER 2018 (www.asercentre.org) or data from the National Achievement Surveys 2017 (Ministry of Human Resource Development. National achievement survey. http://nas.schooleduinfo.in/).
} 
In Pratham's 25-year history, almost all education programs have had a community component. Building on previous experiences and accumulated evidence, Pratham's current flagship program in education, Hamara Gaon (Our Village) has put in place the strongest and longest thrust for building community ownership for children's learning.

In this program, there is an ongoing Pratham presence in the village for a period of at least 3 years. Pratham's method for accelerating learning called Teaching-at-the-Right-Level or TaRL, has considerably evolved over time. The TaRL method is used in a "learning camp" mode in government schools (Banerji et al. 2020). Learning camps are short bursts of activity, 7 or 10 days at time, and repeated at intervals. In any given school, 3-5 learning camps could be done over 3 months. These activities are conducted by Pratham team members and unpaid community volunteers to help children quickly acquire foundational skills. At the same time, children are organized into small groups in their neighborhood where they can do activities together (homework, projects, performances) helped by someone from the immediate community (usually a youth volunteer or a family member). While the learning camp only lasts for 30-50 days, the children's groups meet daily or frequently. The hope is that the group activity supported by an adult will be able to sustain children's learning gains and grow them.

At the heart of the Hamara Gaon intervention is the "village report card", a key instrument for participation and building an understanding of the status of children's learning. By now, the village report card activity has morphed into what is called the Jhat Pat Mohalla Report (roughly translated to mean a quick and fast report) at the mohalla (neighborhood) level. The current process includes the following key steps:

(i) Demonstrate fun activities or learning games that can be done with several children, which not only encourage children from a hamlet to come together, but also show their parents simple activities that can be done at home.

(ii) Do a quick testing using a simplified version of the ASER tool. ${ }^{7}$ Compile a list of children getting testing, along with their results.

(iii) Declare among people present results from the assessment. Encourage a handful of children who read well to come forward and read aloud to show what everyone should aim for.

(iv) Display using a simple poster, the results for the day for that hamlet.

(v) Discuss with community members possible solutions to some of the challenges faced. Encourage them to brainstorm suggestions, distribute responsibilities, and lend support moving forward.

These hamlet-level assessments ended up forming a cornerstone of Pratham's work in villages. By demystifying what "learning" means, the business of learning can be unpacked in ways that the broader community can engage in. This assessment is

\footnotetext{
${ }^{7}$ To ensure things remained simple and fast, the assessment was limited to a simple paragraph (grade 1 level text) for reading, and a subtraction problem for arithmetic. The testing tool was simple while the assessment process was visual and oral, and therefore straightforward, even for parents unable to read themselves; and was intended to encourage others to test as well.
} 
typically followed by several activities, some led by Pratham teams and others by local community actors themselves.

The direct instructional activity in learning camps described above, and the collaborative learning groups of children, are a common feature across many Pratham locations. In addition, other events like community fairs or melas are organized by villagers for school readiness, math, or science. These are done to engage children of all ages and families to celebrate progress and establish a wider community connection. For younger children, mothers' groups are also set up where mothers are oriented on simple activities that they can do at home with children.

These simple activities are critical steps for making the business of education the responsibility of the community at large. In 2019/2020, Pratham's Hamara Gaon intervention was implemented in more than 3500 communities across India. In addition, in 2019, a randomized control trial was also launched in Uttar Pradesh, where elements of this approach started trials, with the aim to dig deeper into how community actors could be convinced to take ownership of their children's learning (Bhattacharjea and Sabates 2020). Another randomized control trial in Assam found promising "value added" in children's learning for villages that had children's groups compared to those that did not. ${ }^{8}$

For the past few years, Pratham has carried out a special experiment in about 1000 villages called "hybrid learning communities" where all children aged 10 and above form part of a neighborhood peer group. There is no Pratham instructional activity in these locations; instead, the children's groups share digital devices like tablets, access a variety of digital content, and perform a range of group activities both with and without technology (World Economic Forum 2019).

Learnings from Pratham's hybrid learning program have been transplanted into other Pratham programs. These hybrid learning communities can be seen as an attempt to enable children and communities to be "future-ready" in five distinct ways:

(i) Recognizing that the curricular space in the school is crowded with academic content leaving little room for other kinds of exposure, in the hybrid learning program, content was designed with three domains in mind: learning for school (academic content); learning for life (a wide variety of everyday domains like art, music, sport, first aid, environment, and other such domains); and learning for work (skills like digital familiarity, communication).

(ii) From focus on individuals, the approach has moved to groups, encouraging groups to work together on tasks and projects.

(iii) The technology used by Pratham does not only receive or transmit content but is also used as a trigger for other activities. For example, the camera and video capability of a device is instrumental in taking forward many projects including documentation of various aspects of community life.

\footnotetext{
${ }^{8}$ This randomized control trial conducted by researchers from the Stockholm School of Economics is yet to be published.
} 
(iv) "Learning by doing" was seen as the primary way of learning rather than "chalk-talk" or rote learning from textbooks, which is usually the mode used in schools.

(v) By placing activities centrally in communities and outside of school, the program explicitly recognized and encouraged participation of family and community members.

Pratham celebrated its 25 th anniversary in 2020 , but it would be wrong to state that it has already developed a sure shot, silver bullet for raising community involvement in education. Like the children and families that Pratham works with, the organization is continuing to learn every day. By helping communities understand, and more importantly, believe in the role they can play in their children's education, the process of empowering families and communities to learn and to help their children learn has started.

Over the years, many state governments have used ASER results to initiate learning improvement programs, and have used ASER-like tools to measure learning improvements. Interestingly, India's New Education Policy 2020 or NEP2020 was launched in 2020, which strongly recommends a national priority for building foundational skills like reading and arithmetic_-goals that ASER has been advocating for over a decade and a half. NEP2020 also highlights the crucial importance of bringing in family and community to help children learn (Ministry of Education 2020).

\subsection{The Coronavirus Disease Crisis and Community Interaction for Children's Learning}

As the COVID-19 pandemic hit the world, a sudden lockdown was imposed on the last week of March 2020 all over India. Movement was heavily restricted as uncertainty and fear gripped the entire country. Schools closed suddenly and with no preparation. Children were stuck at home for an indefinite period of time with limited access to any teaching-learning material or any organized educational activity.

In this crisis, two elements of Pratham's prior work played a vital role in building a new layer of virtual, two-way communication onto the networks that already existed. First, unlike many other education organizations, over the years, Pratham has worked both inside schools and also in communities. The prior investment in building social networks in the community proved to be invaluable during the lockdown and for the entire period that schools were closed. Second, Pratham's past work in making simple digital content available in 11 regional languages proved to be very useful. In March 2020, across all Pratham programs, there was direct contact with approximately 7000 or so rural and urban communities. As an immediate response to the lockdown, Pratham teams started reaching out to parents, youth, and community members whom they had regularly met face-to-face before the crisis. As soon as contact was established, Pratham sent out a message via phone to the family of the child. Initially 
these were WhatsApp messages (instructions and video clips for activities available in the local language). Given the overall atmosphere of tension, Pratham's aim was to connect to children using engaging activities to get their minds off the stress. As far as possible, WhatsApp messages were accompanied at least once a week by an actual phone call for feedback and follow-up from someone in Pratham whom the child and the family knew from before.

Despite relatively high smartphone penetration in rural India, by April, Pratham had realized that many children did not have access to smartphones. Hence to maximize reach, it was essential to be able to connect via basic phones. Another round of outreach was initiated. First contact was established through one person in a village. Through the first contact, outreach was done using phone numbers and contacts in each hamlet of the village. Then through the hamlet contact, an attempt was made to reach as many households as possible.

This systematic strategy of maximizing contact in communities evolved quickly. By June 2020, Pratham was sending out close to 200,000 messages in more than 10,000 rural and urban communities across the country. New and engaging content soon had to be created for basic phones that could be sent through old-tech SMS messages. At least half of the total messages were SMS going to basic phones.

At every stage, as soon as contact was established with an individual or a family, messages began to flow back and forth between the Pratham team member and the contact. The message contained simple activities that the family could do with their children. During the week it was also very common for families to send messages - voice, text, and videos-of what their children were doing based on the instructions that had been sent. This two-way communication became the backbone of the ongoing interactions that have been sustained throughout 2020.

India's stringent lockdown restrictions began to be loosened by July even as the number of COVID-19 cases continued to rise. ${ }^{9}$ Movement within villages had begun and everyone was encouraged to follow social distancing norms and to wear masks. Pratham teams soon started experimenting by running volunteer-led classes in hamlets. With remote guidance by Pratham team members, these hamlet sessions were like mini learning camps run by a local volunteer for children in grades $1-5$. The volunteers had been trained on Pratham's TaRL methodology of grouping children by learning level and doing simple language and math activities. Social distancing norms were strictly followed, and volunteer-led classes also had COVID-19 awareness modules for children. A local volunteer or a local youth typically mobilized 5-10 children. Early data from these experiments show promising results.

Like organizations, governments too were putting together quick coping strategies both in terms of how to reach children, and type of content that could be sent. Digital content especially in regional languages was in demand. Although in prior years, partnerships with government in implementing programs on the ground took time to

\footnotetext{
${ }^{9}$ Confirmed COVID-19 cases for the whole of India at the end of June were 566,840. This number rose to $1,583,792$ by end of July; to $6,145,291$ by end of September; and to $8,137,119$ by end of October 2020 (Source PRS Legislative Research. Details on cases. https://prsindia.org/covid-19/ cases; with source data from the Ministry of Health and Family Welfare.).
} 
germinate, during the pandemic, collaborations moved quickly. In the months since April, Pratham's digital content was used by 14 government education platforms like DIKSHA, or as part of pandemic outreach packages for phones, which went out to children via teachers. (Pratham's SMS message packages were used by three state governments and WhatsApp messages by eight state governments.) As time went by, governments began to move from coping strategies to longer-term efforts that could be sustained. School systems also realized the critical importance of reaching out to children whose families did not have smartphones. Thus, newer strategies included use of traditional media - television programming and radio broadcast (Box 13.2).

\section{Box 13.2 Local Community and State Government Cooperation for Continued Learning During the Coronavirus Disease Lockdowns}

Pratham collaborated with the state governments of Maharashtra and Uttar Pradesh during the coronavirus disease (COVID-19) pandemic to air radio programs that were broadcast in communities. In Bihar, 2 hours of daily programming on television was also provided by Pratham. The Maharashtra government (starting from six districts in Nagpur division) combined Pratham's short message service or SMS messaging with radio programs, and appealed to several departments (including education, women and child welfare, and rural development) in its outreach efforts. The net result was that radio was able to reach an estimated 400,000 children across the state. Many villages broadcast Pratham's radio programs over public loudspeakers, and village councils mobilized local youth to help children in their neighborhoods. In this case, not only was Pratham able to provide remote messaging, but Pratham's models of social mobilization were also incorporated in the government's outreach strategy during the school closures arising from COVID-19.

Source Pratham Education Foundation

From 2014, the main nationwide ASER for schooling and learning was being done in alternate years. 2020 was to be the year for this task. But given the COVID-19 crisis, plans had to be changed. Instead, it seemed much more important to figure out what was going on in the household for children's learning during the prolonged period of school closure. Use of digital means was being quoted in the press, and daily announcements of new apps or software were being reported. Given all this hectic activity to establish remote learning channels, it was essential to take a close look at what was actually reaching children. ASER mounted a national phone survey in September 2020 using the ASER 2018 sample. Over 100,000 households across the country were sampled, and the findings embodied in the Annual Status of Education Report 2020 were released at the end of October 2020 while schools across the country were still closed (ASER Centre 2020). 
The findings were interesting. First, before September, state governments had managed to deliver textbooks for the current grade to well over $80 \%$ of all students. Second, $70 \%$ of households reported that there was someone in the family who could help children with learning activities. The breakdown of this support indicated that in addition to parents, siblings and other family members also contributed. Although smartphone ownership had almost doubled in 2 years from 2018 to 2020 (since the last ASER was done), depending on the state, at least $30 \%$ of families did not have access to smartphones. In the week prior to the survey, about $30 \%$ of families had received some form of learning materials or activities from their children's schools. Although much of this remote messaging came via WhatsApp messages, for public school children, there was a clear effort to reach out via phone calls and home or school visits. The overall picture that emerged was of a society where families and communities were able and eager to help children learn, albeit using traditional means like textbooks and worksheets.

\subsection{Conclusions}

Pratham's work over the last 25 years as well as its experiences during the pandemic have underlined the critical need to involve families and communities as an integral part of any education strategy, be it local or global. The COVID-19 crisis has clearly brought out the fact that there are many resources outside schools that are willing to help children learn. The linear demands of curriculum, or the rigid teaching practices often practiced in school systems in the developing world, leave behind parents and family members who are not educated or who did not get a chance to get schooling. Yet, to teach children at the right level it is important to reach people at their own level to help children.

The COVID-19 crisis has brought forward important lessons for future education strategies. It is clear that learning opportunities in the home-neighborhood-community continuum should be maintained and strengthened as a long-term goal. The ongoing two-way communication with parents has been a big source of learning on what children need and how families can be supported to provide this help. This is an essential piece of the education puzzle and now that clues are available, focus and attention must be used to strengthen this piece.

Clearly, technology has played a major role in making remote connection possible. At the same time, Pratham learned that it was the "hybrid" combination of technology and human interaction that kept processes growing and deepening through the crisis.

Finally, what kept children engaged and families interested were activities that applied and built in different skills in everyday contexts. All of these features will become enduring elements in shaping learning in the future.

In a stark and critical way, the COVID-19 crisis has challenged the key questions of "why", "what", "how", "who", and "when" of education. The core principles that form the framework for school functioning needs urgent change. The crisis 
has visibly demonstrated that the "how" has to change. The need to set up alternative mechanisms to reach children is obvious. From in-school, face-to-face, teaching-learning activities; to SMS messages in a 160-character format, all are modes that need to be in place to cope with the varied contexts in which education will have to be delivered. Digital literacy for the entire population (parents, teachers, children) is a must so that people are prepared to use digital devices, navigate digital pathways, and deal with digital content in different forms.

However, the more fundamental questions that have to be answered are "what" needs to be learned and "why". Why should "learning for school" have greater primacy over "learning for life"? Whether in terms of health services, education, livelihoods, or economic security, economies and societies were not at all well prepared to cope with the current crisis. But learning from this one, how do families and schools prepare children for life in the future and possibly future crises? Experiences from the ground and data from sources like ASER have strongly pointed out that there is a vast cast of characters other than teachers who are available and willing to help with children's learning. The question will be how to harness this energy and effort to help to "build back better".

The real danger facing the world is not so much the learning loss from school closures but what the school system decides to do when schools open. If there is a rush to get back to "business as usual"; e.g., grade-level teaching using grade-level curriculum, there is a strong chance that there may be lasting damage to children's future possibilities. Once schools reopen, reconnecting to peers, friends, and teachers is urgently needed-the re-building of the social fabric underlying education; the celebration and recognition of families and communities in the period of school closure; as well as the building of mechanisms of having them as integral pieces of the education system. Ensuring foundational skills or rebuilding them, as the case may be, will be required. This is the time to take stock of where we have reached, how we have reached, and where and how we want to go in the future.

If we do not learn in a meaningful way from our past experiences and particularly from this deep, current crisis, we will not be able to envision a learning society. A learning society can only be possible when everyone can learn throughout their lifetime to change and adapt as the context requires, and empower others to learn as well. It is only in an environment like this that children will grow, thrive, and become ready for the future.

Acknowledgements The author thanks colleagues Arjun Agarwal, Ranajit Bhattacharyya, and Siddhesh Mhatre without whose timely assistance and invaluable support this chapter would not have been possible.

\section{References}

ASER Centre. ASER reading tools. http://www.asercentre.org/p/141.html.

ASER Centre. Various years. Annual Status of Education Reports. www.asercentre.org. 
Banerjee, A.V. et al. 2010 Pitfalls of participatory programs: Evidence from a randomized evaluation in education in India. American Economic Journal: Economic Policy 2 (1): 1-30. https://www.povertyactionlab.org/evaluation/can-informational-campaigns-raise-awaren ess-and-local-participation-primary-education.

Banerji, R. 2013. Learning for all: The challenge for taking everyone along. In The Right to Learn: Community Participation in Improving Learning. Westport, CT: Save the Children. http://www.savethechildren.org/atf/cf/\%7B9def2ebe-10ae-432c-9bd0df91d2eba74a\% 7D/THE_RIGHT_TO_LEARN.PDF.

Banerji, R., Agarwal, A., and Lakshman, S. 2020. Teaching at the right level: From concern with exclusion to challenges of implementation. Paper commissioned for the 2020 Global Education Monitoring Report, Inclusion and Education. Paris: UNESCO.

Banerji, R., Bhattacharjea, S., and Wadhwa, W. 2013. The annual status of education report (ASER). Research in Comparative and International Education 8 (3): 387-396. https://doi.org/10.2304/ rcie.2013.8.3.387.

Bhattacharjea, S., and Sabates, R. 2020. Engaging schools and communities to support children's learning. https://www.ukfiet.org/2020/engaging-schools-and-communities-to-support-childr ens-learning/.

Government of India, Ministry of Education. New education policy 2020. https://www.education. gov.in/sites/upload_files/mhrd/files/NEP_Final_English_0.pdf.

Government of India, Ministry of Human Resource Development. National achievement survey. http://nas.schooleduinfo.in/.

People's Action for Learning. www.palnetwork.org.

PRS Legislative Research. Details on cases. https://prsindia.org/covid-19/cases. Accessed October 2020.

Vagh, S. B. 2012. Validating the ASER testing tools: Comparisons with reading fluency measures and the Read India Measures. http://img.asercentre.org/docs/Aser\%20survey/Tools\%20validat ing_the_aser_testing_tools_oct_2012_2.pdf.

World Economic Forum. 2019. Schools of the future. http://www3.weforum.org/docs/WEF_Sch ools_of_the_Future_Report_2019.pdf.

The opinions expressed in this chapter are those of the author(s) and do not necessarily reflect the views of the Asian Development Bank, its Board of Directors, or the countries they represent.

Open Access This chapter is licensed under the terms of the Creative Commons Attribution-NonCommercial 3.0 IGO license (http://creativecommons.org/licenses/by-nc/3.0/igo/) which permits any noncommercial use, sharing, adaptation, distribution and reproduction in any medium or format, as long as you give appropriate credit to the Asian Development Bank, provide a link to the Creative Commons license and indicate if changes were made.

Any dispute related to the use of the works of the Asian Development Bank that cannot be settled amicably shall be submitted to arbitration pursuant to the UNCITRAL rules. The use of the Asian Development Bank's name for any purpose other than for attribution, and the use of the Asian Development Bank's logo, shall be subject to a separate written license agreement between the Asian Development Bank and the user and is not authorized as part of this CC-IGO license. Note that the link provided above includes additional terms and conditions of the license.

The images or other third party material in this chapter are included in the chapter's Creative Commons license, unless indicated otherwise in a credit line to the material. If material is not included in the chapter's Creative Commons license and your intended use is not permitted by statutory regulation or exceeds the permitted use, you will need to obtain permission directly from the copyright holder. 